\title{
Synergistic Effect of Mo, W, Mn and Cr on the Passivation Behavior of a Fe-Based Amorphous Alloy Coating
}

\author{
Wan-Ping Tian ${ }^{1,2} \cdot$ Hong-Wang Yang ${ }^{1} \cdot$ Suo-De Zhang $^{2}$
}

Received: 4 January 2017/Revised: 26 January 2017 / Published online: 14 June 2017

(C) The Chinese Society for Metals and Springer-Verlag GmbH Germany 2017

\begin{abstract}
In this work, the electrochemical behaviors of SAM2X5 Fe-based amorphous alloy coating and hard chromium coating were comparatively studied in $3.5 \mathrm{wt} \% \mathrm{NaCl}$ solution. In comparison with the hard chromium coating, the SAM2X5 coating exhibited a wider and stable passive region with lower passive current density in the potentiodynamic polarization and showed a considerably lower current density at different anodic potentials in the potentiostatic polarization. In order to understand the passivation mechanism of the Fe-based amorphous coating, the components of the passive films formed at various polarization potentials were examined by X-ray photoelectron spectroscopy. The synergistic effect of $\mathrm{Mo}, \mathrm{W}, \mathrm{Mn}$ and $\mathrm{Cr}$ in the passive films was systemically analyzed. It has been revealed that Mo and $\mathrm{W}$ facilitate the formation of compact and stable $\mathrm{Cr}_{2} \mathrm{O}_{3}$ passive film at lower potentials, and the substantial enrichment of $\mathrm{Mn}$ in the passive film enhances the passivation ability at relatively higher potentials. The deep understanding of the passivation characteristics in multicomponent alloy systems could provide a guide for the design of corrosion-resistant amorphous alloy coatings for engineering applications.
\end{abstract}

\section{KEY WORDS: Amorphous alloy; Metallic coating; Passivation; Surface film; X-ray photoelectron} spectroscopy (XPS)

\section{Introduction}

Fe-based amorphous alloys have attracted much attention because of the attractive combination of properties including high mechanical strength, excellent corrosion and wear resistance, good magnetic properties and

Available online at http://link.springer.com/journal/40195

Hong-Wang Yang

hwyang2000@hotmail.com

$\bowtie$ Suo-De Zhang

sdzhang@imr.ac.cn

1 School of Materials Science and Engineering, Shenyang University of Technology, Shenyang 110178, China

2 Shenyang National Laboratory for Materials Science, Institute of Metal Research, Chinese Academy Sciences, Shenyang 110016, China relatively low material cost $[1,2]$. The chemical homogeneity and absence of crystalline defects, such as grain boundaries, second phases, dislocations, which are susceptible to chemical attack, make the amorphous alloy be an excellent corrosion-resistant material [3]. However, due to the limited size and intrinsic brittleness, the Fe-based amorphous alloys are not suitable as structural components. Fortunately, these limitations could be overcome when Febased amorphous alloys are used as surface protective coatings $[4,5]$. For the fabrication of Fe-based amorphous coatings, the widely recognized method is thermal spraying techniques, e.g., high velocity air fuel (HVAF). To date, the amorphous coatings have shown promising applications in aggressive environments, where the corrosion and wear resistance are needed to compare with traditional protective coatings, such as hard chromium coating.

Over the past 100 years, traditional hard chromium coatings have been used as corrosion-resistant coating for 
various industrial applications [6]. However, chromium coatings have restricted to limited thickness and often contain microcracks, which limit their use in severe corrosive environment [7]. Additionally, due to the toxic nature of the preparation process, there is pressing demand to explore new coatings produced by cost-effective environment friendly technique $[8,9]$. High velocity air fuel (HVAF) technology is considered as one of the most competitive thermal spray technologies to substitute hard chromium plating technology. Recently, HVAF method has been successfully used to produce Fe-based corrosionresistant coatings, such as $\mathrm{Fe}_{48} \mathrm{Cr}_{15} \mathrm{Mo}_{14} \mathrm{C}_{15} \mathrm{~B}_{6} \mathrm{Y}_{2}$ [10], $\mathrm{Fe}_{42.87} \mathrm{Cr}_{15.98} \mathrm{Mo}_{16.33} \mathrm{C}_{15.94} \mathrm{~B}_{8.88} \quad[11], \quad \mathrm{Fe}_{49.7} \mathrm{Cr}_{18} \mathrm{Mn}_{1.9}$ $\mathrm{Mo}_{7.4} \mathrm{~W}_{1.6} \mathrm{~B}_{15.2} \mathrm{C}_{3.8} \mathrm{Si}_{2.4}$ [12]. Among many Fe-based amorphous alloy systems, the SAM2X5 $\left(\mathrm{Fe}_{49.7} \mathrm{Cr}_{18} \mathrm{Mn}_{1.9}\right.$ $\mathrm{Mo}_{7.4} \mathrm{~W}_{1.6} \mathrm{~B}_{15.2} \mathrm{C}_{3.8} \mathrm{Si}_{2.4}$ at.\%) has received increasing interest for many engineering applications [13, 14]. Wang et al. [15] and Farmer et al. [16] developed the thermalspraying SAM2X5 amorphous alloy coating with good corrosion resistance, high hardness, and exceptional neutron-absorption cross sections. Zhang et al. [12] and Hashimoto [17] reported that the long-term corrosion behavior of the Fe-based amorphous coating and the corrosion mechanism from the standpoint of porosity defect. Wang et al. [15] investigated the corrosion behavior of the passive film of the SAM2X5 metallic glass in acidic and neutral solutions using electrochemical measurements, atomic force microscopy, and X-ray photoelectron spectroscopy (XPS). It is known that in the SAM2X5 alloy system, the addition of $\mathrm{B}, \mathrm{Si}$ and $\mathrm{C}$ could enhance glass forming ability, while high concentrations of $\mathrm{Cr}$, Mo and $\mathrm{W}$ could improve corrosion resistance [14]. It has been recognized that the SAM2X5 alloy with a dense coating generally possess excellent corrosion resistance, which benefit to the corrosion-resistant components. However, the systematic study on the synergistic effect of these corrosion-resistant elements is still not fully understood. In addition, the effect of $\mathrm{Mn}$ on the corrosion resistance in this alloy system is scarcely reported. Thus, deep understanding of the passivation mechanism in multicomponent alloy systems is of utmost importance for designing of corrosionresistant amorphous alloy coatings for engineering applications.

These corrosion-resistant components may result in spontaneous passivation due to the formation of surface film, which acts as a barrier for preventing the ion exchange between the metal and the environment [17]. Concerning the aspect of alloy elements affecting the passivation behavior, it is well known that the addition of $\mathrm{Cr}$ could greatly enhance the corrosion resistance of Fe-based alloys due to the formation of compact and stable chromium-enriched passive film [18-20]. The role of Mo in corrosion resistance of alloys has been investigated for many years, but there is still controversial. Several studies [21] have found no enrichment of Mo in passive film of stainless steel and amorphous alloys, while other researchers maintained that the $\mathrm{MoO}_{2}$ exists in the passive film as the major passivating species [22, 23]. With respect to $\mathrm{W}$ element, the use of it as an anodic inhibitor would enhance pitting resistance at lower concentrations, which lead to the notion that enhanced pitting resistance is dependent upon maintaining the $\mathrm{W}$ ion at the metal/solution interface [24]. While Bui et al. have reported that the addition of $\mathrm{W}$ in $\mathrm{Fe}-\mathrm{Cr}-\mathrm{Ni}$ systems extends the passive range and reduces the passive current density by interaction with water and formation of insoluble $\mathrm{WO}_{3}$ phase, which enhances the stability of oxide layers in chloride-containing media [25]. But the mechanism of the effect of $\mathrm{W}$ on the passivation behavior in amorphous alloy systems is not very clear. The role of $\mathrm{Mn}$ in Fe-based alloys is usually related to $\mathrm{MnS}$ inclusion, which is considered to deteriorate the uniformity of structure and composition in alloys [26, 27]. But for the amorphous alloy systems, it has been reported that $\mathrm{Mn}$ improved the corrosion resistance and inhibited the growth of the corrosion pits [28, 29]. Thus, for the multicomponent amorphous alloy system, the influence of $\mathrm{Mn}$ on corrosion behavior need to be further clarified. From the above studies, it can be seen that most of the work try to understand the role of alloy elements in corrosion behavior in the crystalline alloy systems. Thus, the crystalline phases and crystalline defects probably confuse the intrinsic effect of alloy elements. On the other hand, throughout the passivation process for alloys, the roles of aforementioned corrosion-resistant elements are lack of comprehensive consideration.

The aim of this work is to understand the role of each corrosion-resistant elements and elucidate the synergistic effect of the corrosion-resistant elements $\mathrm{Cr}, \mathrm{Mo}, \mathrm{Mn}$ and W in the SAM2X5 Fe-based amorphous coating and to compare its corrosion characteristics with conventional chromium coating. The components of the passive films formed at various polarization potentials were examined by XPS to understand the passivation mechanism in multicomponent Fe-based amorphous and chromium coatings. Our results provide a clear comprehension on the governing principles about the formation of passive films at various corrosion conditions. It is envisaged that the findings of this work would be crucial in designing corrosion-resistant amorphous alloys coatings for various industrial applications.

\section{Experimental}

\subsection{Material and Samples Preparation}

The materials used in this work were $\mathrm{Fe}_{49.7} \mathrm{Cr}_{18} \mathrm{Mn}_{1.9}$ $\mathrm{Mo}_{7.4} \mathrm{~W}_{1.6} \mathrm{~B}_{15.2} \mathrm{C}_{3.8} \mathrm{Si}_{2.4}$ (at.\%) amorphous alloy. The powders were prepared by heating up the master alloys to 
about $1350{ }^{\circ} \mathrm{C}$ using a close-coupled annulus nozzle with a melt delivery inner diameter of $3 \mathrm{~mm}$, and then high-pure argon gas atomization at a dynamic pressure of $7 \mathrm{MPa}$. The atomized powders with nominal size of $22-53 \mu \mathrm{m}$ were used as feedstock material. The powders were sprayed on mild steel plates with a size of $350 \mathrm{~mm} \times 150 \mathrm{~mm} \times 5 \mathrm{~mm}$ by AK-07 spray gun (Kermetico, USA) with AcuKote HVAF thermal spray system. All the substrates were mechanically ground, degreased by acetone, dried in air, and subsequently grit-blasted prior to thermal praying. The detailed spraying parameters are as follows: fuel flow rate is $0.12-0.14 \mathrm{~m}^{3} / \mathrm{min}$, hydrogen flow rate is $0.035 \mathrm{~m}^{3} / \mathrm{min}$, and nitrogen flow rate is $0.027 \mathrm{~m}^{3}$ / min, respectively; the spraying distance is $180-240 \mathrm{~mm}$ and the traverse velocity is $500 \mathrm{~mm} / \mathrm{s}$. The spraying experiments were conducted in the open air. A conventional bath containing $250 \mathrm{~g} / \mathrm{L}$ of $\mathrm{CrO}_{3}$ and $2.5 \mathrm{~g} / \mathrm{L}$ of $\mathrm{H}_{2} \mathrm{SO}_{4}$ was used for the hard chromium plating. The operating parameters were as follows: a plating current density of $50 \mathrm{~A} \mathrm{dm}^{-2}$, a constant anodic current density of $8 \mathrm{~A} \mathrm{dm}^{-2}$ in the reverse pulsating current cycle, a plating time of $10 \mathrm{~min}$, a temperature of $50 \pm 1{ }^{\circ} \mathrm{C}$ and a $\mathrm{pH}$ of 4 .

The coating surfaces were ultrasonically cleaned in acetone and mechanically ground with SiC paper, then polished to $0.5 \mu \mathrm{m}$ diamond paste before being tested to remove any surface contamination. The dimensions of tested coating samples for potentiostatic measurement are $5 \mathrm{~mm} \times 5 \mathrm{~mm} \times 5 \mathrm{~mm}$. The coating samples for potentiodynamic polarization and potentiostatic polarization measurements were covered with silicone except the tested coating surface.

\subsection{Testing Methods}

The microstructure of the coated samples was examined by scanning electron microscopy (SEM, Quanta 600) coupled with energy-dispersive spectroscopy (EDS). X-ray diffraction (XRD) analysis of the polished coating surfaces (perpendicular to the coating-substrate interface) was undertaken on a Rigaku D/max 2400 diffractometer (Tokyo, Japan) with monochromatic $\mathrm{Cu}_{\alpha}$ radiation ( $\lambda=0.1542 \mathrm{~nm}$ ). Thermal properties of Fe-based coating were investigated by differential scanning calorimetry (DSC, Perkin-Elmer DSC-7) in a continuous heating mode at a rate of $20 \mathrm{~K} / \mathrm{min}$ under atmosphere.

The corrosion behavior of the coatings was evaluated with open-circuit potential measurements (OCP), potentiostatic and potentiodynamic polarization technique. Prior to the electrochemical measurements, all samples were wet-ground to 5000 grit using $\mathrm{SiC}$ paper and then were polished using $0.5-\mu \mathrm{m}$ diamond paste in deionized water then cleaned in deionized water and dried in the warm air. Electrochemical measurements were conducted in $3.5 \mathrm{wt} \%$
$\mathrm{NaCl}$ aqueous solution using a potentiostat-galvanostat EG \& G Princeton Applied Research model 2273. Solutions were made from reagent-grade chemicals mixed with deionized water. All electrochemical tests were performed at room temperature in a three electrode cell with platinum plate counter-electrode and saturated calomel reference electrode (SCE). Prior to all electrochemical measurements, the samples were immersed in the solution for about $1 \mathrm{~h}$ until attaining a stable corrosion potential. Potentiodynamic polarization measurements were performed in a wide range from about $-100 \mathrm{mV}_{\mathrm{SCE}}$ to OCP to $1.2 \mathrm{~V}_{\mathrm{SCE}}$ at a potential sweep rate of $20 \mathrm{mV} / \mathrm{min}$. For evaluating passive films at various applied potentials, potentiostatic measurements at potentials of $0.0 \mathrm{~V}_{\mathrm{SCE}}, 0.6 \mathrm{~V}_{\mathrm{SCE}}$, and $0.8 \mathrm{~V}_{\mathrm{SCE}}$ were conducted in $3.5 \mathrm{wt} \% \mathrm{NaCl}$ solution open to air for $100 \mathrm{~min}$. Each test was repeated at least three times for the repeatability and reliability.

For analyzing the compositions of passive films formed at $0.0,0.6$ and $0.8 \mathrm{~V}_{\mathrm{SCE}}$, the samples were taken out immediately after potentiostatic polarization for X-ray photoelectron spectroscopy (XPS) analysis using an ESCALAB 250 photoelectron spectrometer and a monochromatic Al $K \alpha$ excitation $(h v=1486.6 \mathrm{eV})$. Quantitative information was calculated from the survey spectra using standard Scofield sensitivity factors. The compositions of the passive films were quantitatively determined from the characteristic spectra using the integrated intensities of photoelectrons. Binding energies were calibrated using the carbon contamination with $\mathrm{C} 1 s$ peak value of $284.6 \mathrm{eV}$ and the standard binding energies of $\mathrm{Fe}$ $2 p$, Cr $2 p$, Mo $3 d$, Mn $2 p$ and $\mathrm{W} 4 f$ core levels were analyzed by a least-squares fit with XPS peak analytical software 4.1. The Shirley method was employed for background subtraction of all the peaks. XPS ion beam sputtering with argon was used to analyze the depth profiles of the surface films and the sputtering rate was estimated to be $0.1 \mathrm{~nm} \mathrm{~s}^{-1}$ [30].

\section{Results and Discussion}

\subsection{Microstructure Characterization}

Figure 1 presents the typical morphology of the SAM2X5 alloy coated mild steel. From the SEM micrograph of the coating in Fig. 1a, it can be seen that the powders were well-melted and there is almost no un-melted powders on the coating surface. As can be seen from the cross section for the coated sample (Fig. 1b), the coating exhibits a uniform structure with a thickness of $\sim 580 \mu \mathrm{m}$ and the bonding between the coating and the substrate is quite well. The porosity for this coating is calculated using image analysis method from 10 cross-sectional views of the 

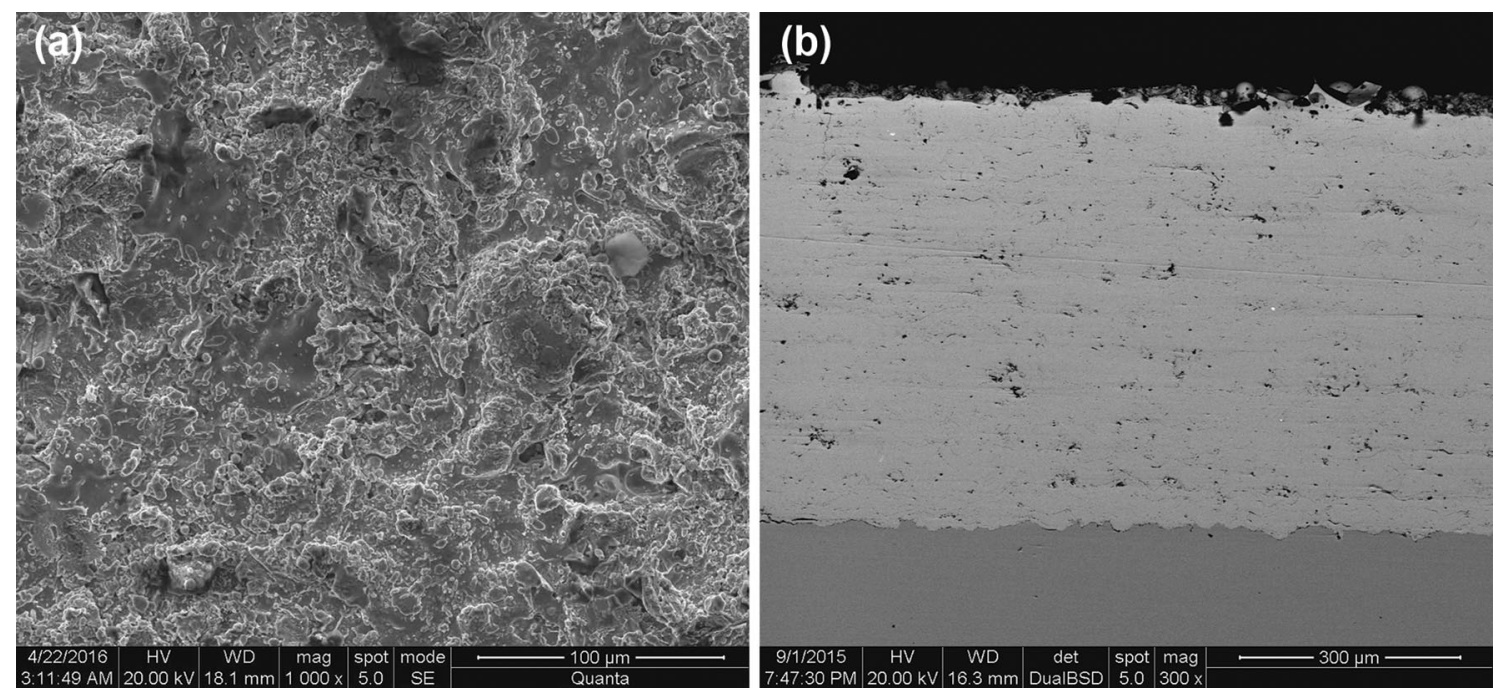

Fig. 1 Typical SEM micrographs of the surface a, the cross section $\mathbf{b}$ for the SAM2X5 amorphous coating prepared by HVAF method

coating obtained by SEM. The average porosity calculated is $0.79 \%$ for the SAM 2 X 5 coating. The XRD patterns of HVAF sprayed Fe-based coating are illustrated in Fig. 2. The XRD pattern for the Fe-based coating presents the diffuse pattern and no district crystalline peaks, indicating its basically amorphous structure. The DSC curve of the assprayed coating is presented in inset of Fig. 2. Upon heating, two distinct exothermic reactions at 620 and $700{ }^{\circ} \mathrm{C}$ were observed for the alloy, indicating that the coating undergoes two crystallization reactions during devitrification.

\subsection{Electrochemical Test}

Figure 3 shows the potentiodynamic polarization curves of the SAM2X5 coating and the hard chromium coating in

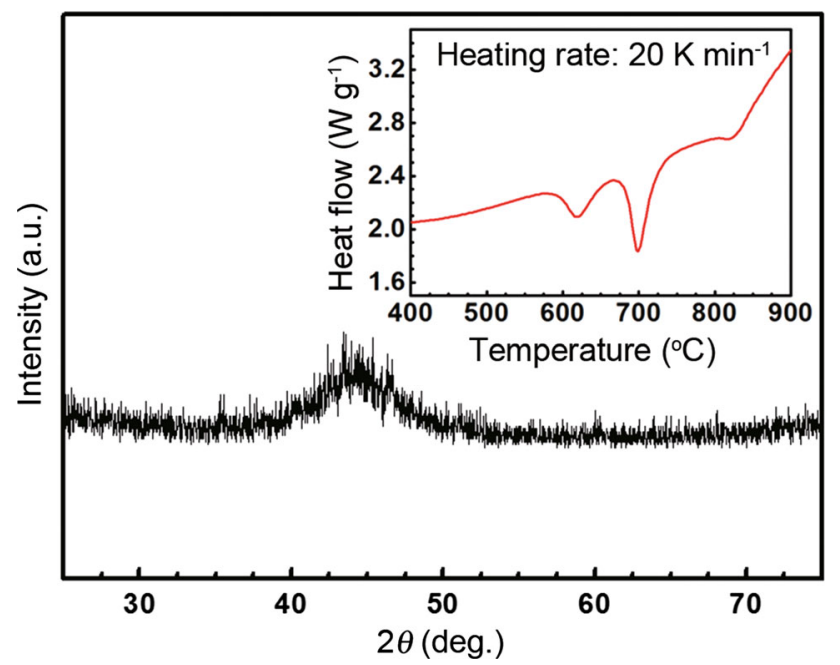

Fig. 2 XRD pattern of the SAM2X5 Fe-based amorphous coating. Inset DSC continuous heating curve of the coating
$3.5 \mathrm{wt} \% \mathrm{NaCl}$ solutions at room temperature. It can be seen that the SAM2X5 coating could spontaneously passivate in the solutions with a wide passivation region (exceeding $1300 \mathrm{mV}$ ) and lower passivation current density $\left(i_{\text {pass }}\right)$ on the order of $10^{-5} \mathrm{~A} \mathrm{~cm}{ }^{-2}$. Some little transient peaks in the curve of SAM $2 X 5$ coating may be caused by the process of pit initiation and repassivation. The hard chromium coating can also spontaneously passivate with the assistance of $\mathrm{Cr}$, but the polarization curve exhibits much more unstable than the SAM2X5 amorphous coating, especially at lower potential region. As can be observed, the current density of hard chromium coating increased gradually with the applied potentials and up to a stable value until $0.6 \mathrm{~V}_{\mathrm{SCE}}$. Besides, the passive current density of the hard chromium coating was about one order of magnitude higher than that of SAM2X5 coating in the

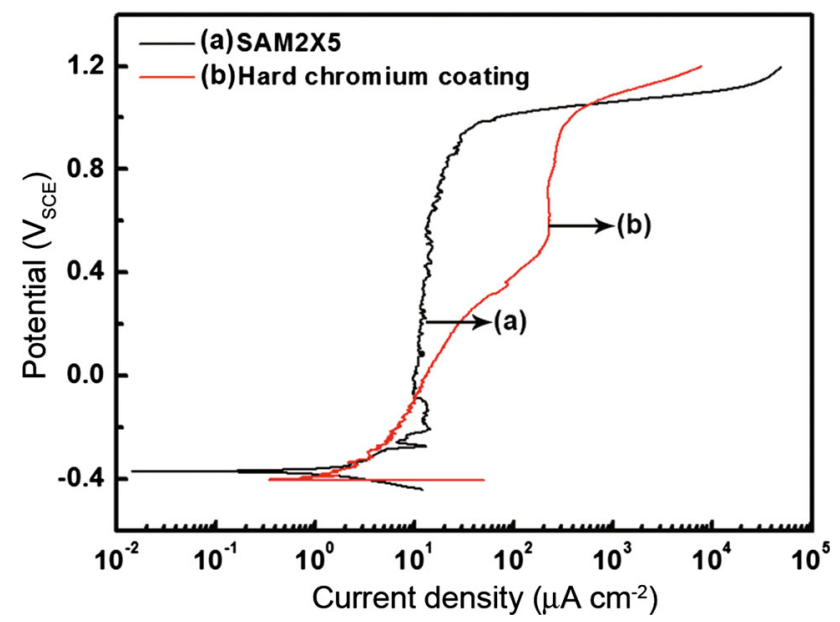

Fig. 3 Potentiodynamic polarization curves of the SAM2X5 Febased amorphous coating $a$, hard chromium coating $b$ in $3.5 \mathrm{wt} \%$ $\mathrm{NaCl}$ solution 
relatively high potential ranges (higher than $0.6 \mathrm{~V}_{\mathrm{SCE}}$ ). Thus, the two coatings show different potentiodynamic polarization behavior and the discrepancy is apparent as the applied potentials change. For further understanding this different passivation behavior of the two coatings, potentiostatic polarization tests have been conducted at three representatively selected potentials of $0.0,0.6$ and $0.8 \mathrm{~V}_{\mathrm{SCE}}$.

Figure 4 exhibits the potentiostatic polarization curves of SAM2X5 coating and hard chromium coating at each selected potential for 100-min immersion. The background currents were usually retained in tens of nano-amperes (nA) with an acceptable variation [31, 32]. Figure 4a shows that the SAM2X5 coating could form an stable passive film against corrosive attack and its current density during immersion is kept on the order of $10^{-7} \mathrm{~A} \mathrm{~cm}^{-2}$ throughout the whole immersion, while the anodic current density of the hard chromium coating starts to rise after 1000-s immersion and increases to $2.5 \times 10^{-4} \mathrm{~A} \mathrm{~cm}^{-2}$ at the end. At higher potentials $0.6 \mathrm{~V}_{\mathrm{SCE}}$ and $0.8 \mathrm{~V}_{\mathrm{SCE}}$ (Fig. $4 \mathrm{~b}$, c), the SAM2X5 coatings are kept a relatively low current density of about $10^{-5} \mathrm{~A} \mathrm{~cm}^{-2}$ despite the appearance of some little current transients. By contrast, the current density of the hard chromium coating is unstable and more than one order of magnitude higher than that of SAM2X5 coating during the whole tests. The SAM2X5 coating exhibits more stable passivation with a relatively low current density, indicating a more protective passive film formed on this coating compared with that of the hard chromium coating during potentiostatic polarization. Summed up, at lower potential region, the hard chromium coating could not form a steady and protective passive film but the passive film formed on the SAM2X5 coating exhibits more protectiveness. At higher potential region, both coatings could form protective passive films, whereas the SAM2X5 coating shows more stable corrosion resistance. The stable passive film of the SAM2X5 coating probably benefits from the addition of various alloying elements in this amorphous alloy coating. To explore the synergistic effect of the corrosion-resistant elements in the passive film, the chemical analysis of the passive films formed at the representatively selected polarization potentials was conducted by XPS technique.

\subsection{Chemical Analysis of Passive Film}

The synergistic effect of various elements on corrosion behavior depends on the distribution and the chemical states of these elements in the passive films. The samples for XPS analysis were potentiostatic polarized at representative potentials of $0 \mathrm{~V}_{\mathrm{SCE}}, 0.6 \mathrm{~V}_{\mathrm{SCE}}$ and $0.8 \mathrm{~V}_{\mathrm{SCE}}$ in $3.5 \mathrm{wt} \% \mathrm{NaCl}$ solutions for $100 \mathrm{~min}$.
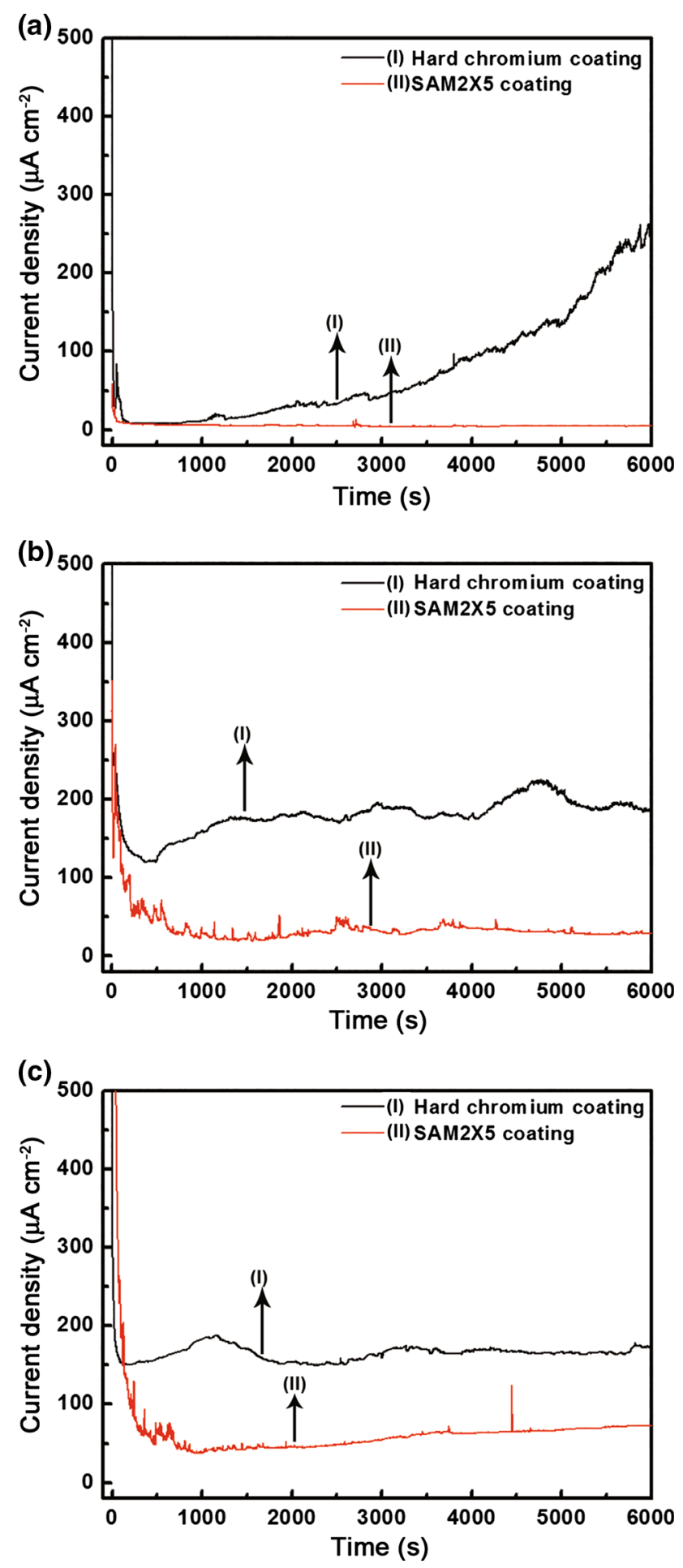

Fig. 4 Potentiostatic polarization curves of the hard chromium coatings (I) and the SAM2X5 Fe-based amorphous coatings (II) in $3.5 \mathrm{wt} \% \mathrm{NaCl}$ solution for $100 \mathrm{~min}$ at: a $0.0 \mathrm{~V}_{\mathrm{SCE}}$, b $0.6 \mathrm{~V}_{\mathrm{SCE}}$, c $0.8 \mathrm{~V}_{\mathrm{SCE}}$

Figure 5 shows the normalized XPS survey spectra of the passive films formed under different potentials in the $\mathrm{NaCl}$ solution. Some main peaks marked in the spectra 
indicate the presences of $\mathrm{Fe}, \mathrm{Cr}, \mathrm{Mo}, \mathrm{Mn}, \mathrm{W}, \mathrm{C}, \mathrm{B}, \mathrm{Si}$ and O. Although these spectra are overall similar, the differences exist in both the intensities and the precise positions of each peak. These differences result from the different chemical states of the element and the ratio of different valence for the detected element. In order to understand the components of the passive films, the XPS results are separated into contributions of different chemical states for the main corrosion-resistant elements $\mathrm{Fe}, \mathrm{Cr}, \mathrm{Mo}, \mathrm{Mn}$ and $\mathrm{W}$. The assigned peak position for each state of these elements for the different polarization potentials is consistent.

The high-resolution spectra of $\mathrm{Cr} 2 p_{3 / 2}$ for the surfaces of both coatings are presented in Fig. 6. From the $\mathrm{Cr} 2 p_{3 / 2}$ spectra for the SAM2X5 coating (Fig. 6a, c, e), it can be seen that the components of $\mathrm{Cr}$ element in the surface films formed at lower potential $\left(0 \mathrm{~V}_{\mathrm{SCE}}\right)$ and at higher potentials $\left(0.6 \mathrm{~V}_{\mathrm{SCE}}\right.$ and $\left.0.8 \mathrm{~V}_{\mathrm{SCE}}\right)$ are different. The surface film formed at lower potentials contains metallic state $\mathrm{Cr}$ and the oxidation state $\mathrm{Cr}$ consisting of $\mathrm{Cr}_{2} \mathrm{O}_{3}$ and $\mathrm{Cr}(\mathrm{OH})_{3}$. While the higher potentials formed surface films only contain oxidation state $\mathrm{Cr}\left(\mathrm{Cr}_{2} \mathrm{O}_{3}\right.$ and $\left.\mathrm{Cr}(\mathrm{OH})_{3}\right)$, absence of the metallic state $\mathrm{Cr}$. This is probably related to the $\mathrm{Cr}$ diffusion from the alloy matrix to the film/metal interface [33]. For the hard chromium coatings, the $\mathrm{Cr} 2 p_{3 / 2}$ spectra of the surface films formed at all three potentials are similar, composing of the metallic state $\mathrm{Cr}$, oxidation state $\mathrm{Cr}_{2} \mathrm{O}_{3}, \mathrm{Cr}(\mathrm{OH})_{3}$ and $\mathrm{Cr}_{7} \mathrm{C}_{3}$. The existence of $\mathrm{Cr}_{7} \mathrm{C}_{3}$ is attributed to the in-order crystallization process of excess carbon atom in the $\mathrm{Cr}-\mathrm{C}$ layer through intermediate $\mathrm{Cr}-\mathrm{C}$ deposit [34].

The spectra of $\mathrm{Fe} 2 p_{3 / 2}$ and $\mathrm{Mn} 2 p_{3 / 2}$ are shown in Fig. 7a, c, e and Fig. 7b, d, f, respectively. The spectrum of $\mathrm{Fe} 2 p_{3 / 2}$ is comprised of metallic $\mathrm{Fe}$ and oxidation state

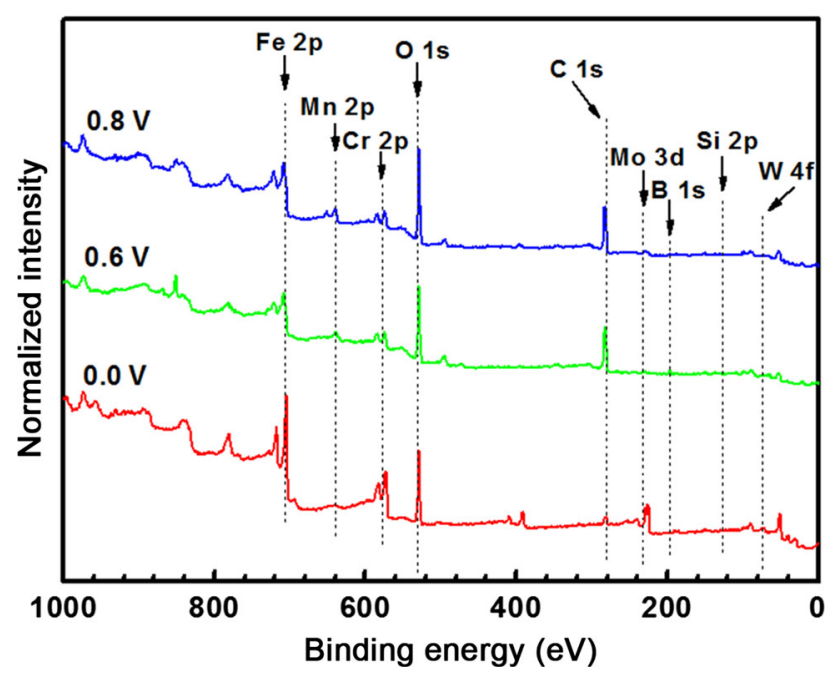

Fig. 5 XPS survey spectra for SAM2X5 Fe-based amorphous coatings anodic polarized at $0 \mathrm{~V}_{\mathrm{SCE}}, 0.6 \mathrm{~V}_{\mathrm{SCE}}$ and $0.8 \mathrm{~V}_{\mathrm{SCE}}$ in $3.5 \mathrm{wt} \% \mathrm{NaCl}$ solution
$\mathrm{Fe}^{2+}$ and $\mathrm{Fe}^{3+}$. The assigned peak position of metallic $\mathrm{Fe}$ detected from the surface films formed at various potentials is consistent, but the peak positions of oxidation state ferrum are slightly different. For the film formed at the higher potentials $\left(0.6 \mathrm{~V}_{\mathrm{SCE}}\right.$ and $\left.0.8 \mathrm{~V}_{\mathrm{SCE}}\right)$, the peak positions of $\mathrm{Fe}^{2+}$ and $\mathrm{Fe}^{3+}$ are located at $\mathrm{BE}=709.3 \mathrm{eV}$ and $\mathrm{BE}=710.9 \mathrm{eV}$, respectively. However, at the lower potentials $\left(0.0 \mathrm{~V}_{\mathrm{SCE}}\right)$, both the $\mathrm{Fe}^{2+}$ and $\mathrm{Fe}^{3+}$ have a relatively low binding energy, and the corresponding peak positions are $\mathrm{BE}=708.2 \mathrm{eV}$ and $\mathrm{BE}=710.3 \mathrm{eV}$, respectively. Indeed, the lower binding energy peaks can be considered to be the ferrous and ferric iron contribution under the mixed oxide $\mathrm{Fe}_{3} \mathrm{O}_{4}$, which is the transition stage of $\mathrm{FeO}$ oxidized to $\mathrm{Fe}_{2} \mathrm{O}_{3}$. When the samples were polarized at more positive potentials, the $\mathrm{Fe}_{3} \mathrm{O}_{4}$ in the surface film could be transformed to $\mathrm{Fe}_{2} \mathrm{O}_{3}$. These results are consistent with the reported work, where the peak positions of $\mathrm{Fe}^{2+}$ and $\mathrm{Fe}^{3+}$ are at $\mathrm{BE}=708.2 \mathrm{eV}$ and $\mathrm{BE}=710.3 \mathrm{eV}$, respectively [35]. In addition, it is worth noting that the ratio of $\mathrm{Fe}^{3+} / \mathrm{Fe}^{2+}$ gradually decreases with increasing the applied potentials as shown in Fig. 8. This may arise because of the readily dissolving of the highvalence iron species at relatively high polarization potentials. As can be seen from the spectra of Mn $2 p_{3 / 2}$ (Fig. 7b, $\mathrm{d}, \mathrm{f}$ ), the spectrum of $\mathrm{Mn}$ is comprised of metallic Mn, $\mathrm{Mn}^{2+}$ and $\mathrm{Mn}^{4+}$. The high-valence $\mathrm{Mn}$ species also decrease as the applied potentials increase.

The spectra of Mo $3 d$ and W $4 f$ are shown in Fig. 8. The curves fitting for Mo and W spectra become complicated due to the overlap of the oxidation states of the two elements region. The area ratio between the Mo $3 d_{5 / 2}$ and Mo $3 d_{3 / 2}$ was fixed to 1.5 , and the energy split was fixed to $3.1 \mathrm{eV}$ [36]. The area ratio between the $\mathrm{W} 4 f_{7 / 2}$ and $\mathrm{W} 4 f_{5 / 2}$ was fixed to $4 / 3$ with the energy split of $2.0 \mathrm{eV}$ [24]. The fitting results of Mo $3 d$ are presented in Fig. 8a, c and e. At $0.0 \mathrm{~V}_{\mathrm{SCE}}$ and $0.6 \mathrm{~V}_{\mathrm{SCE}}$, a relatively high quantity of $\mathrm{Mo}^{4+}$ exists in the passive films. These $\mathrm{MoO}_{2}$ film or a similar hydrated product acts as an effective barrier against the diffusion of species through the film, and they may also assist to hinder the selective dissolution of the metals beneath them [37]. As the potentials rise to $0.8 \mathrm{~V}_{\mathrm{SCE}}$, there is only $\mathrm{Mo}^{6+}$ ions could be detected in the passive film. This $\mathrm{MoO}_{3}$ can inhibit the pits propagation and it is effective in repassivating $\mathrm{Fe}$ undergoing pitting corrosion. Meanwhile, the soluble hexavalent molybdate $\mathrm{MoO}_{4}^{2-}$ plays an important role in preventing the ingress of $\mathrm{C}^{-}$ ions by enriching in exterior regions of film [17, 21].

As can be seen in Fig. 8b, d, f, the metallic W exists in the passive films formed under various potentials. It is well known that the addition of tungsten could decrease the current density in the passive region. The soluble hexavalent tungstate ions, another existent form of $\mathrm{W}^{6+}$, also exist 
(a)

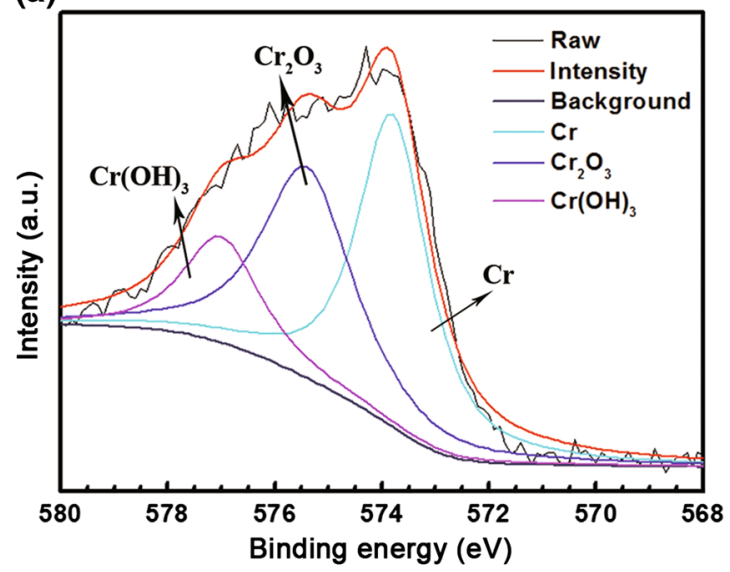

(c)

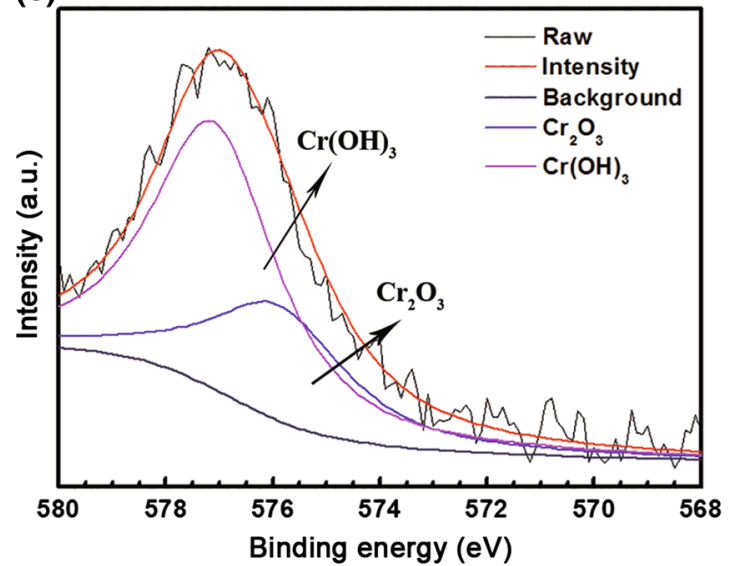

(e)

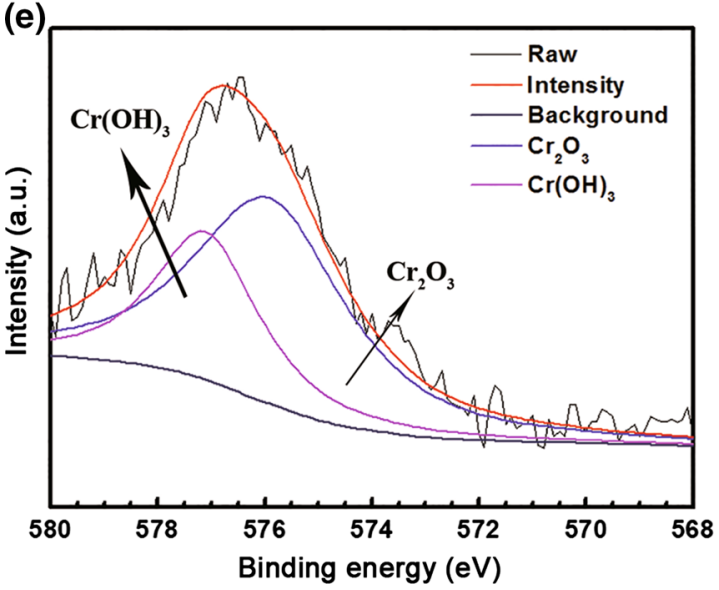

(b)

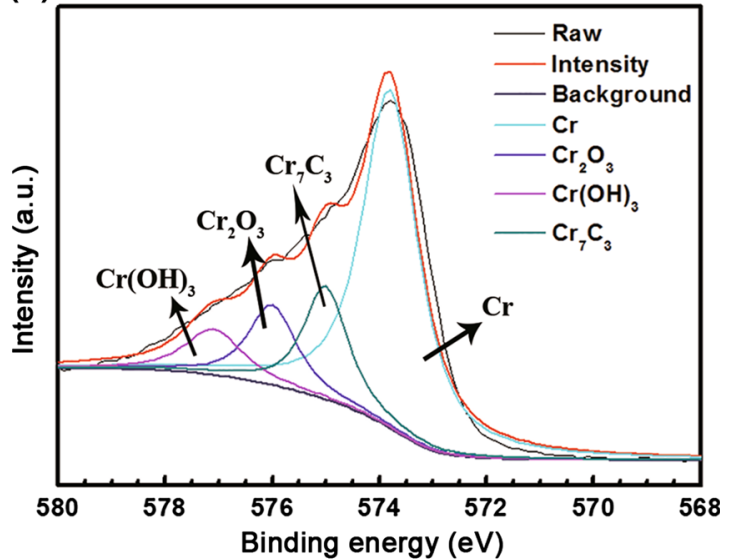

(d)
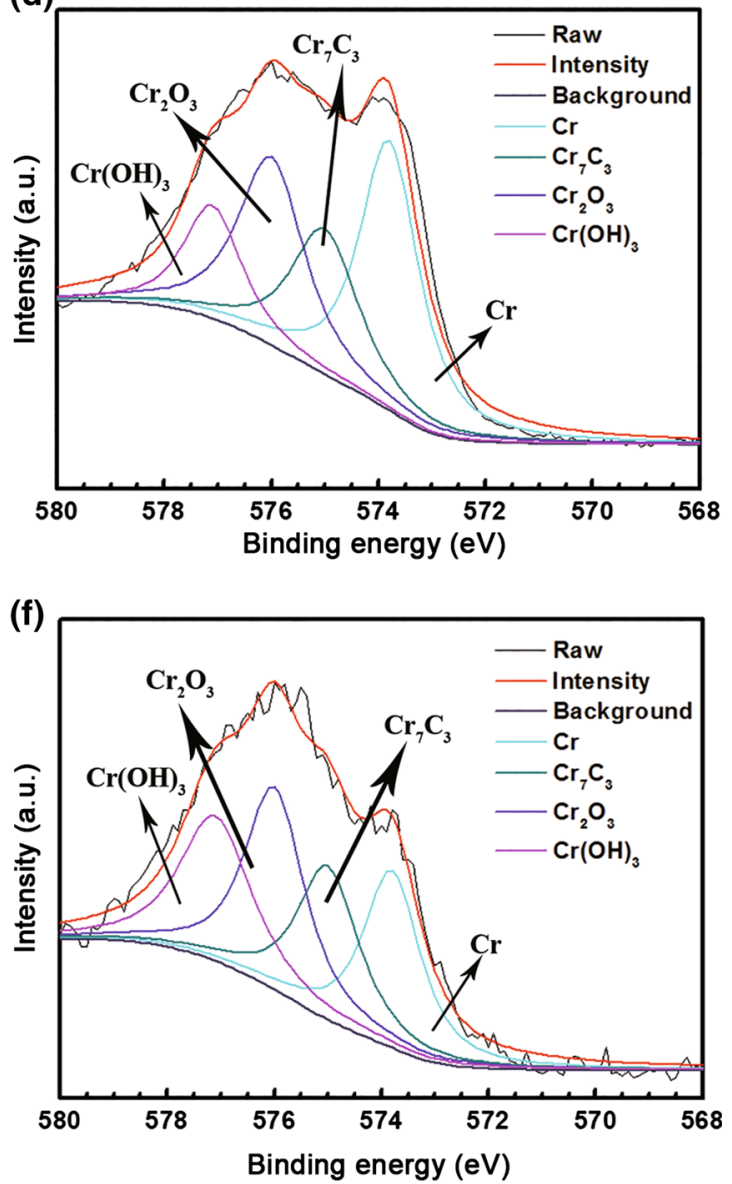

Fig. 6 The detailed XPS spectra of $\mathrm{Cr} 2 p_{3 / 2}$ of the passive films formed on the SAM2X5 Fe-based amorphous coatings a, c, e and the hard chromium coatings $\mathbf{b}, \mathbf{d}, \mathbf{f}$ after potentiostatic polarization at $0.0 \mathrm{~V}_{\mathrm{SCE}} \mathbf{a}, \mathbf{b}, 0.6 \mathrm{~V}_{\mathrm{SCE}} \mathbf{c}, \mathbf{d}, 0.8 \mathrm{~V}_{\mathrm{SCE}} \mathbf{e}, \mathbf{f}$ for $100-\mathrm{min}$ in $3.5 \mathrm{wt} \% \mathrm{NaCl}$ solution

in solutions at high potential. The hexavalent tungsten species, similar to hexavalent molybdate ions, can affect the ion-selective property of the duplex passive film [38]. Besides, the relative ratio of hexavalent tungsten and molybdenum increase in passive region with increasing the polarization potentials. This could improve the protectiveness of the passive films at relatively high potentials $[39,40]$. The Fe $2 p_{3 / 2}$, Cr $2 p_{3 / 2}$, Mo $3 d_{5 / 2}$, Mn $2 p_{3 / 2}$ and $\mathrm{W}$ $4 f_{5 / 2}$ photoelectron peak position and peak assignment are unified and summarized in Table 1. 
(a)

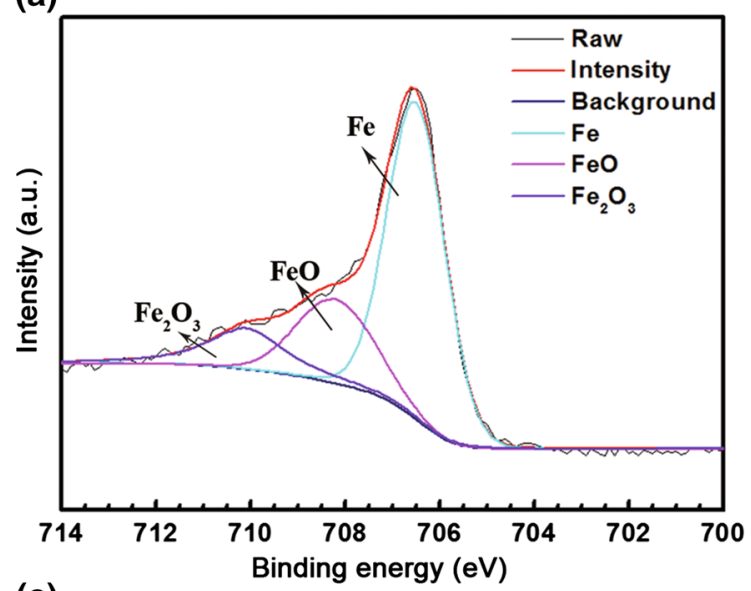

(c)

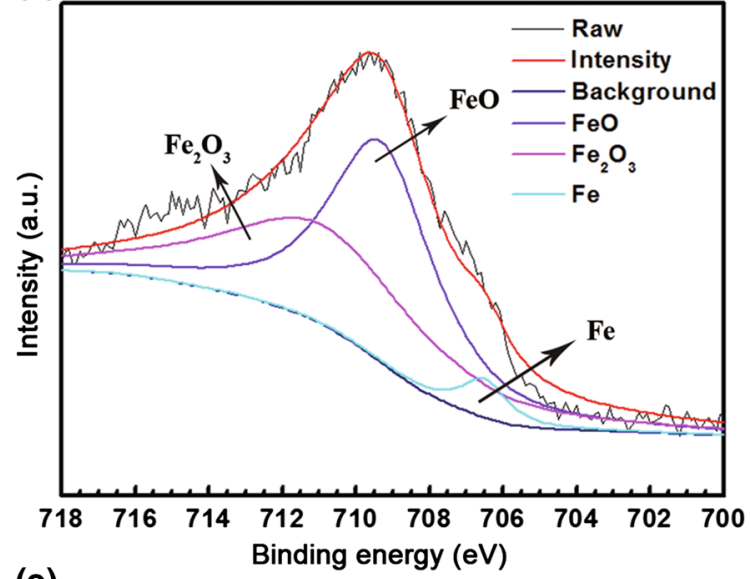

(e)

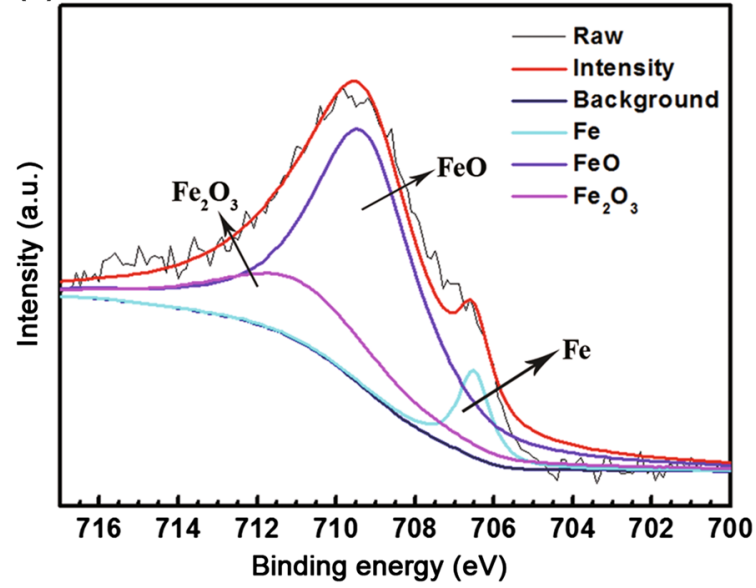

(b)

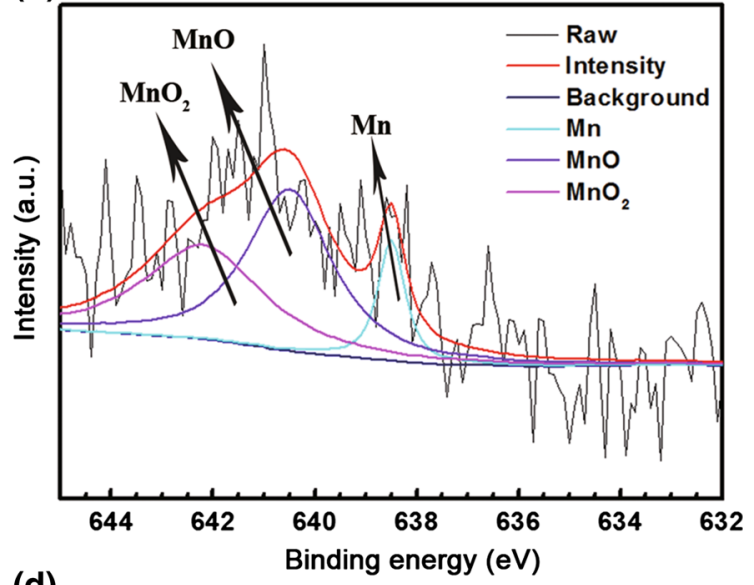

(d)

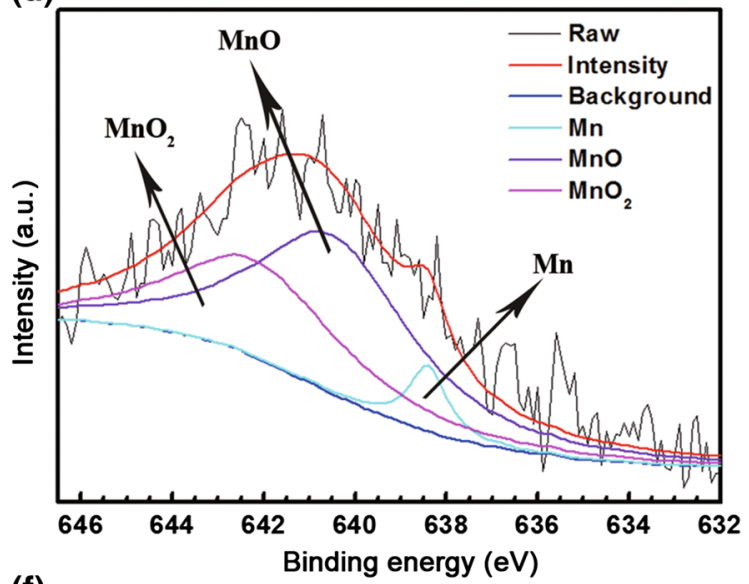

(f)

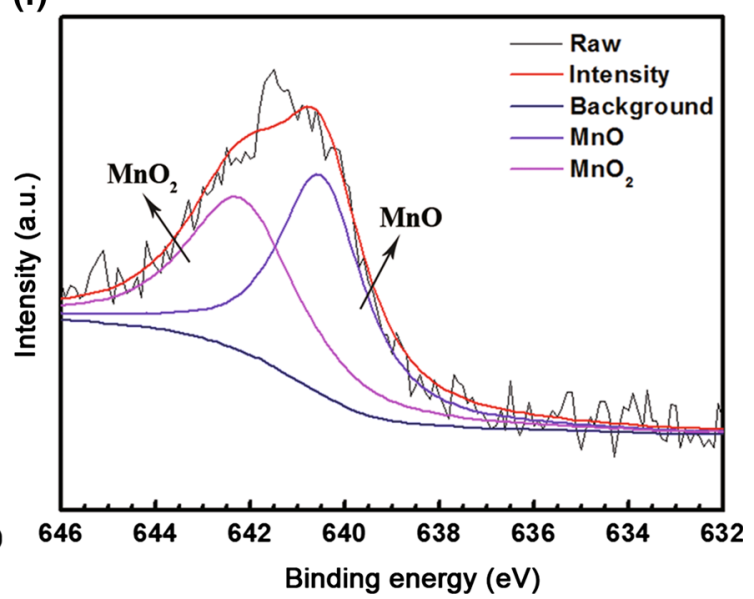

Fig. 7 The detailed XPS spectra of Fe $2 p_{3 / 2} \mathbf{a}, \mathbf{c}, \mathbf{e}, \mathrm{Mn} 2 p_{3 / 2} \mathbf{b}, \mathbf{d}, \mathbf{f}$ of the passive films formed on the SAM2X5 Fe-based amorphous coatings after polarization at $0.0 \mathrm{~V}_{\mathrm{SCE}} \mathbf{a}, \mathbf{d}, 0.6 \mathrm{~V}_{\mathrm{SCE}} \mathbf{c}, \mathbf{d}, 0.8 \mathrm{~V}_{\mathrm{SCE}} \mathbf{e}, \mathbf{f}$ for $100 \mathrm{~min}$ in $3.5 \mathrm{wt} \% \mathrm{NaCl}$ solution

\subsection{Synergistic Effect of Corrosion-Resistant \\ Elements in Fe-Based Amorphous Coating}

As discussed above, the passive films formed at various applied potentials possess different components and exhibit different protectiveness. In order to understand the excellent passivation behavior of Fe-based amorphous coating, quantifying constituents of the passive films and its underlying interface are of paramount importance. For XPS quantitative analysis, it can be assumed that the oxide state components are derived from the passive films and the metallic state locate at the oxide/metal interface [41, 42]. The thickness of the oxide layer was determined through XPS results. The main constituent, i.e., Fe was used to 
(a)

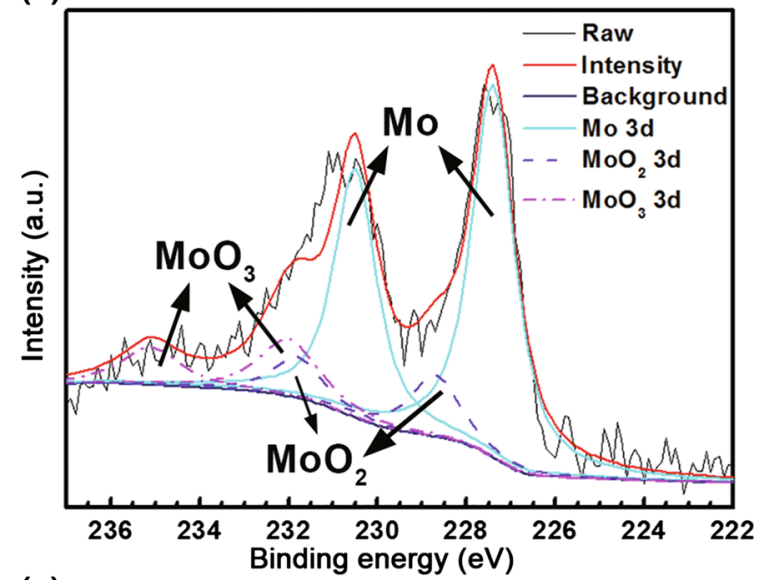

(c)

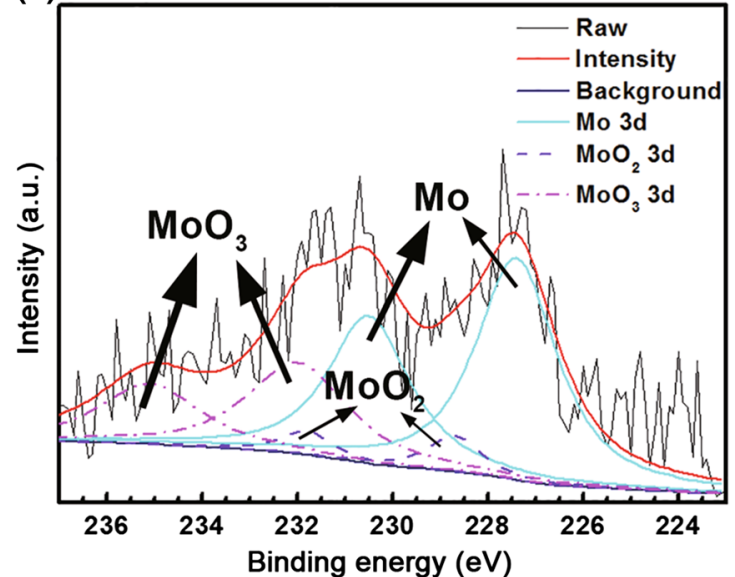

(e)

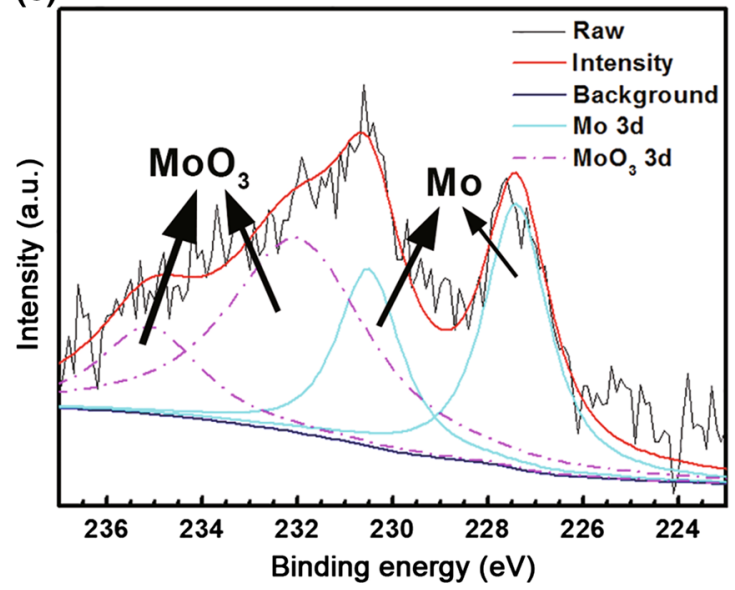

(b)

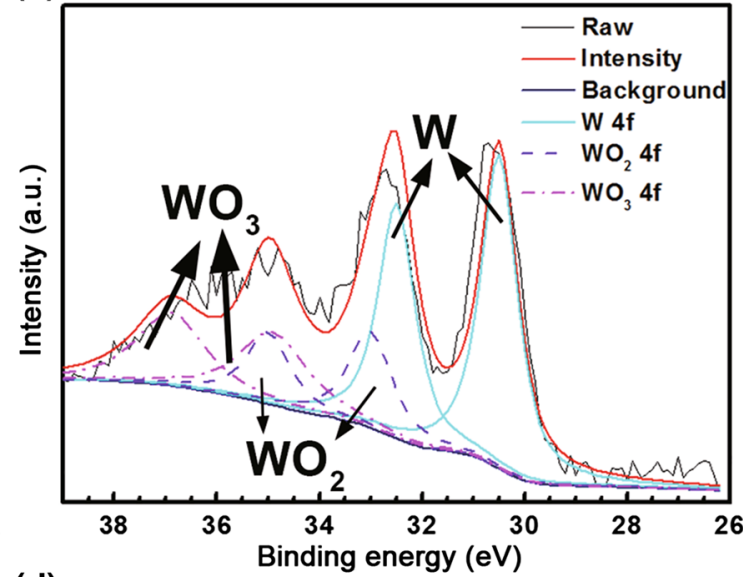

(d)

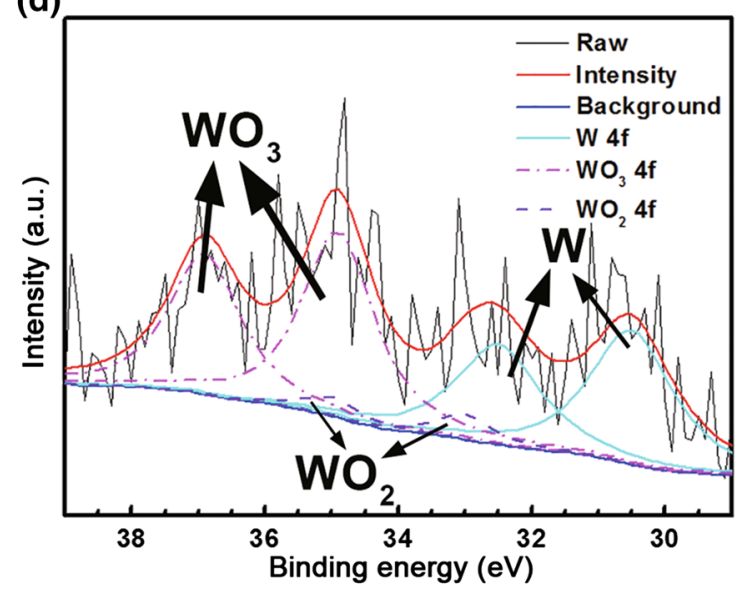

(f)

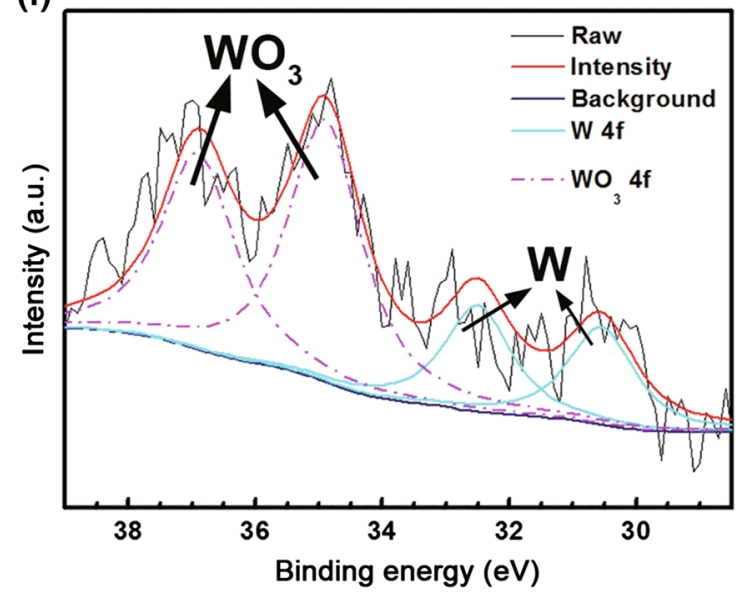

Fig. 8 The detailed XPS spectra of Mo $3 d \mathbf{a}, \mathbf{c}, \mathbf{e}, \mathrm{W} 4 f \mathbf{b}, \mathbf{d}, \mathbf{f}$ of the passive films formed on the SAM2X5 Fe-based amorphous coatings after polarization at $0.0 \mathrm{~V}_{\mathrm{SCE}} \mathbf{a}, \mathbf{b}, 0.6 \mathrm{~V}_{\mathrm{SCE}} \mathbf{c}, \mathbf{d}, 0.8 \mathrm{~V}_{\mathrm{SCE}} \mathbf{e}, \mathbf{f}$ for $100 \mathrm{~min}$ in $3.5 \mathrm{wt} \% \mathrm{NaCl}$ solution

determine the thickness of oxide layer [43], the depth profiles with different potentials are shown in Fig. 9. In this case, the oxide thickness was measured at the point where the concentration profiles between intersect oxidation $\mathrm{Fe}$ and metallic Fe. It can be clearly observed that the thickness of passive films is very different. The thickness of oxide layers is proportional to etch time. The thickness of the passive film formed at $0.0 \mathrm{~V}_{\mathrm{SCE}}$ is the thinnest, while those of the films formed at $0.6 \mathrm{~V}_{\mathrm{SCE}}$ and $0.8 \mathrm{~V}_{\mathrm{SCE}}$ are 17 times and 11 times thicker than that at $0.0 \mathrm{~V}_{\mathrm{SCE}}$, respectively. Therefore, the quantitative composition analysis of passive films formed at various applied potentials could be estimated. Figure 10 shows the cations fraction of the oxidized components in the passive films under various 
Table 1 XPS peak position and peak assignment for the components of the passive films formed on the Fe-based amorphous coating surface

\begin{tabular}{|c|c|c|c|}
\hline Spectra & \multicolumn{2}{|c|}{ Peak assignment } & Peak position $(\mathrm{eV})$ \\
\hline \multirow[t]{5}{*}{ Fe $2 p_{3 / 2}$} & $\mathrm{Fe}(0)$ & & 706.5 \\
\hline & $\mathrm{FeO}$ & & 709.3 \\
\hline & $\mathrm{Fe}_{2} \mathrm{O}_{3}$ & & 710.9 \\
\hline & $\mathrm{Fe}_{3} \mathrm{O}_{4}$ & $\mathrm{FeO}$ & 708.2 \\
\hline & & $\mathrm{Fe}_{2} \mathrm{O}_{3}$ & 710.3 \\
\hline \multirow[t]{4}{*}{$\mathrm{Cr} 2 p_{3 / 2}$} & $\operatorname{Cr}(0)$ & & 573.8 \\
\hline & $\mathrm{Cr}_{2} \mathrm{O}_{3}$ & & 575.9 \\
\hline & $\mathrm{Cr}(\mathrm{OH})_{3}$ & & 577.1 \\
\hline & $\mathrm{Cr}_{7} \mathrm{C}_{3}$ & & 575.0 \\
\hline \multirow[t]{3}{*}{ Mo $3 d_{3 / 2}$} & $\operatorname{Mo}(0)$ & & 227.4 \\
\hline & $\mathrm{MoO}_{2}$ & & 228.7 \\
\hline & $\mathrm{MoO}_{3}$ & & 232.0 \\
\hline \multirow[t]{3}{*}{ W $4 f_{5 / 2}$} & $\mathrm{~W}(0)$ & & 30.5 \\
\hline & $\mathrm{WO}_{2}$ & & 33.0 \\
\hline & $\mathrm{WO}_{3}$ & & 34.9 \\
\hline \multirow[t]{3}{*}{$\operatorname{Mn} 2 p_{3 / 2}$} & $\operatorname{Mn}(0)$ & & 638.4 \\
\hline & $\mathrm{MnO}$ & & 640.5 \\
\hline & $\mathrm{Mn}_{2} \mathrm{O}_{3}$ & & 642.2 \\
\hline
\end{tabular}

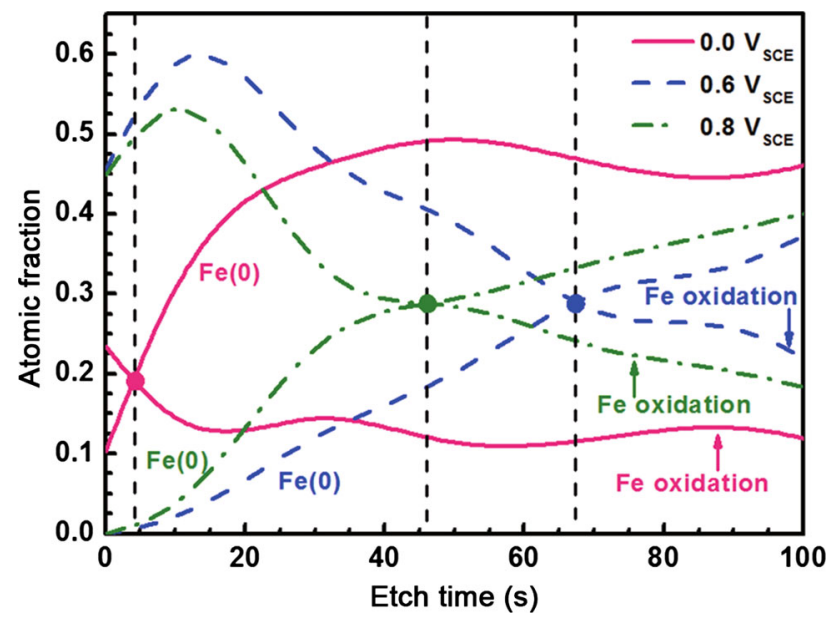

Fig. 9 Depth profiles of the surface layer of SAM2X5 amorphous coatings after exposure to $3.5 \mathrm{wt} \% \mathrm{NaCl}$ solution for $100 \mathrm{~min}$. The vertical dash lines indicate the boundaries for the different samples at various potentials

applied potentials for Fe-based amorphous coating. In this figure, the width of stripes represent approximates the thickness of the passive films. Furthermore, the corresponding cationic fractions of various components in the passive films formed at each potential are summarized in Table 2 . From Table 2, it can be clearly observed that the

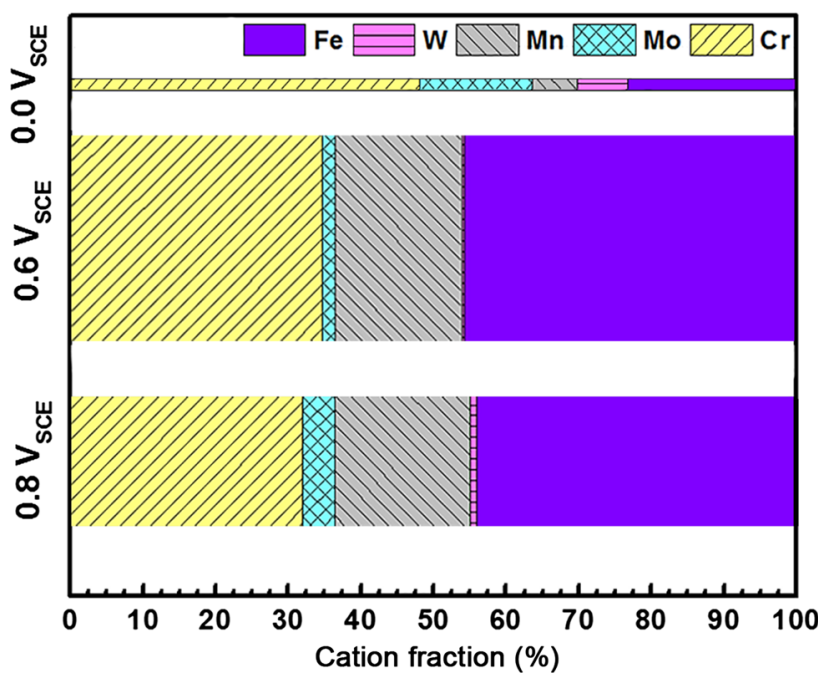

Fig. 10 Cations fraction of $\mathrm{Fe}, \mathrm{Cr}, \mathrm{Mo}, \mathrm{W}$ and $\mathrm{Mn}$ in the passive films formed on the SAM2X5 Fe-based amorphous coating after polarized at various potentials for $100 \mathrm{~min}$

passive film formed at $0.8 \mathrm{~V}_{\mathrm{SCE}}$ is thinner than that of $0.6 \mathrm{~V}_{\mathrm{SCE}}$. This might be due to the preferential dissolution of oxides with high valence, which is consistent with the results reported by Bojinov et al. [44]. The degree of enrichment various corrosion-resistant elements in passive films under various potentials are different. The variation tendency in the content of Mo and $\mathrm{W}$ is similar, and both elements are enriched in the passive film formed at $0.0 \mathrm{~V}_{\mathrm{SCE}}$ while depleted at $0.6 \mathrm{~V}_{\mathrm{SCE}}$ and finally increased at $0.8 \mathrm{~V}_{\mathrm{SCE}}$. This variation is consistent with formation of $\mathrm{Cr}_{2} \mathrm{O}_{3}$ viz. the $\mathrm{Mo}$ and $\mathrm{W}$ first enrich in the passive film and facilitate the formation of compact $\mathrm{Cr}_{2} \mathrm{O}_{3}$ film during the initial stage of anodic polarization at $0.0 \mathrm{~V}_{\mathrm{SCE}}$. Furthermore, the variation of $\mathrm{Fe}$ shows a trend that is opposite to the change of Mo and $\mathrm{W}$ components. This indicates that the additions of Mo and $\mathrm{W}$ in $\mathrm{Fe}-\mathrm{Cr}$ alloys can lower the activity of $\mathrm{Fe}$ element and increase the pitting resistance of the alloys [45]. Besides, at higher potentials $0.8 \mathrm{~V}_{\mathrm{SCE}}$, the hexavalent Mo and $\mathrm{W}$ suppress transpassivation dissolution of the alloy. Additionally, the dissolvable $\mathrm{MoO}_{4}^{2-}$ and $\mathrm{WO}_{4}^{2-}$ anions improve the ion-selective property of the passive films and resist attack of chloride ion.

It can also be observed from Fig. 10 that Mn enriched in the passive films apparently at higher polarization potentials. This indicates that the Mn element can facilitate the passivation at the relatively high potentials, and similar results were also reported by Zhang et al. [28]. Furthermore, it can be clearly seen from Fig. 11 that the content of Mn cations in the passive film formed at low potentials $\left(0 \mathrm{~V}_{\mathrm{SCE}}\right)$ is below $4 \%$ at all etching times while it significantly increases at higher potentials. It is worth noting that at $0.6 \mathrm{~V}_{\mathrm{SCE}}$, the manganese content in the surface film before sputtering is much higher than that of after $10 \mathrm{~s}$ 
Table 2 Cationic fractions of detected corrosion-resistant elements by XPS for the Fe-based amorphous coating

\begin{tabular}{|c|c|c|c|c|c|c|c|c|c|c|}
\hline \multirow[t]{2}{*}{ Applied potential } & \multicolumn{10}{|c|}{ Cationic fractions of the components in the passive film } \\
\hline & $\mathrm{Cr}_{2} \mathrm{O}_{3}$ & $\mathrm{Cr}(\mathrm{OH})_{3}$ & $\mathrm{MoO}_{2}$ & $\mathrm{MoO}_{3}$ & $\mathrm{WO}_{2}$ & $\mathrm{WO}_{3}$ & $\mathrm{MnO}$ & $\mathrm{MnO}_{2}$ & $\mathrm{FeO}$ & $\mathrm{Fe}_{2} \mathrm{O}_{3}$ \\
\hline $0.0 \mathrm{~V}_{\mathrm{SCE}}$ & 0.703 & 0.297 & 0.578 & 0.422 & 0.521 & 0.574 & 0.246 & 0.754 & 0.602 & 0.398 \\
\hline $0.6 \mathrm{~V}_{\mathrm{SCE}}$ & 0.322 & 0.678 & 0.164 & 0.836 & 0.189 & 0.0811 & 0.342 & 0.658 & 0.538 & 0.462 \\
\hline $0.8 \mathrm{~V}_{\mathrm{SCE}}$ & 0.669 & 0.331 & 0 & 1 & 0 & 1 & 0.527 & 0.423 & 0.732 & 0.268 \\
\hline
\end{tabular}

sputtering, indicating that the $\mathrm{Mn}$ is enriched in outermost layer of the passive film. The enrichment of $\mathrm{Mn}$ in the film can compensate the relative scarcity of $\mathrm{Cr}_{2} \mathrm{O}_{3}$ at this potential and enhance the passivation ability of the $\mathrm{Fe}$ based amorphous coating. At various sputtering time, the content of $\mathrm{Mn}$ in the film formed at $0.8 \mathrm{~V}_{\mathrm{SCE}}$ was much higher than that formed at $0.6 \mathrm{~V}_{\mathrm{SCE}}$ (Fig. 11), indicating that the Mn element is enriched in the internal layer at this high potentials. Generally, in the bilayer structure of the passive film for Fe-based alloys, the high-valence species constitute the outer film and the low valence species form the inner part [46]. Thus, at the high potentials, e.g., $0.8 \mathrm{~V}_{\mathrm{SCE}}$, the enrichment of $\mathrm{MnO}$ combined with $\mathrm{FeO}$ in the inner passive films could inhibit the growth of the metastable pits [28].

Figure 12 schematically shows the synergistic effect of $\mathrm{Mo}, \mathrm{W}, \mathrm{Mn}$ and $\mathrm{Cr}$ in the $\mathrm{Fe}$-based amorphous coating. In each stage of the passive process, the compact $\mathrm{Cr}_{2} \mathrm{O}_{3}$ acts as the major barrier layer. At the lower anodic potentials, Mo and $\mathrm{W}$ play an essential role in forming insoluble oxide film and facilitate the enrichment of $\mathrm{Cr}_{2} \mathrm{O}_{3}$ in the passive films. As the anodic potential increases to a high value, e.g., $0.6 \mathrm{~V}_{\mathrm{SCE}}, \mathrm{Mn}$ oxides substantially enrich in the

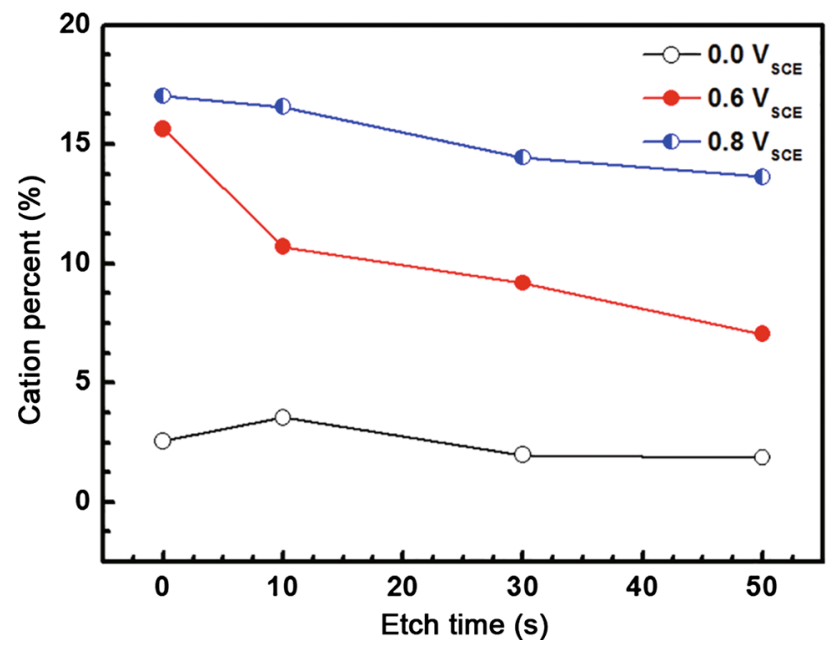

Fig. 11 Proportion of $\mathrm{Mn}$ to the corrosion-resistant elements $(\mathrm{Fe}, \mathrm{Cr}$, $\mathrm{Mo}, \mathrm{W}$ and $\mathrm{Mn}$ ) in the passive films formed on the SAM2X5 Febased amorphous coatings after polarized at various potentials for $100-$ min in $3.5 \mathrm{wt} \% \mathrm{NaCl}$ solution

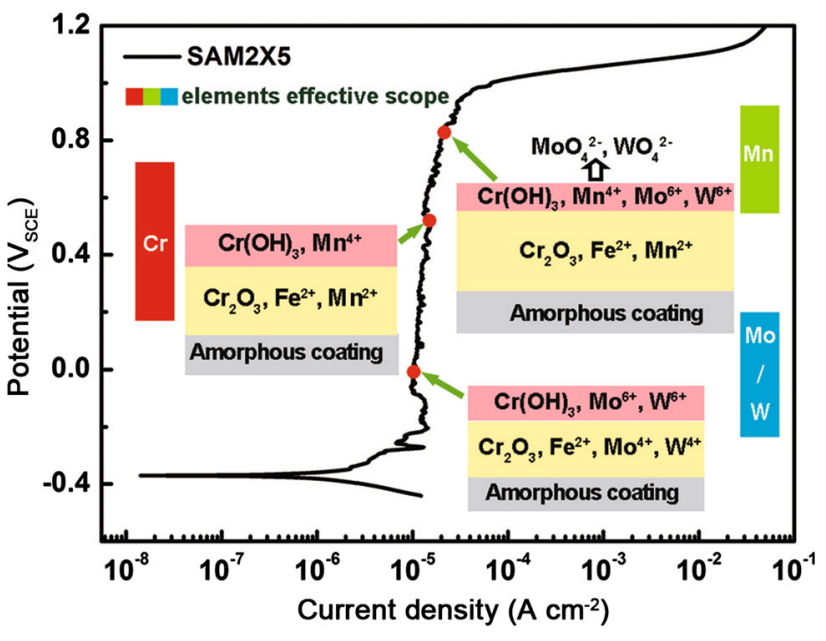

Fig. 12 Schema of the synergistic effect of $\mathrm{Mo}, \mathrm{W}, \mathrm{Mn}$ and $\mathrm{Cr}$ on the passivation behavior in multicomponent Fe-based amorphous alloys during the anodic polarization in a chloride-containing solution

passive film, especially in the outer passive film, that greatly improve its stability and protectiveness. As the anodic potentials continue to increase, e.g., at $0.8 \mathrm{~V}_{\mathrm{SCE}}$, the enrichment of $\mathrm{Mn}$ in the passive film was further enhanced and large amount of $\mathrm{Cr}_{2} \mathrm{O}_{3}, \mathrm{FeO}$ and $\mathrm{MnO}$ got enriched in the inner passive film. Consequently, stable passivation of the Fe-based amorphous coating was achieved. Meanwhile, at this high potentials, Mo and $\mathrm{W}$ exist in the passive film only in the form of hexavalence, improving the protectiveness of the passive films. At relatively high potential range, the soluble hexavalent ions of Mo and $\mathrm{W}$ change the ion-selective property of the passive film, combined with the compact barrier layer of $\mathrm{Cr}_{2} \mathrm{O}_{3}$, providing the resistance against $\mathrm{Cl}^{-}$ion ingress. Therefore, the synergistic effect of these elements could assist to stabilize the passive films under various applied potentials in neutral $3.5 \mathrm{wt} \% \mathrm{NaCl}$ solutions.

The implications of this work for the design of a corrosion-resistant amorphous coating are as follows. The amorphous alloy coatings are characterized as the high solubility of corrosion-resistant components beyond the limited solid solution for the traditional crystalline alloys. Therefore, a tunable performance, such as corrosion resistance, can be obtained by a proper addition of some 
elements. The passivation range of $\mathrm{Cr}$ is wide and the chromium oxides are stable and compact, so the sufficient addition of $\mathrm{Cr}$ could guarantee the stability and protectiveness of passive film. But in some aggressive environment, the alloy is unable to achieve an instant passivation due to the preferential dissolution of $\mathrm{Cr}$ in the active potential region of $\mathrm{Cr}$. Under this circumstance, the addition of sufficient corrosion-resistant elements is in a passive state in this potential region is essential to prevent from the active dissolution of the $\mathrm{Cr}$ component, facilitating the passivation of the alloys. For example, in the present study, the addition of Mo and $\mathrm{W}$ stabilizes the passive films formed at low potentials. Simultaneously, at high potential region, the addition of some corrosion-resistant elements such as Mn could form protective oxide, which is beneficial to prolonging the passivation range of alloys.

\section{Conclusions}

The electrochemical behavior of $\mathrm{HVAF}$ sprayed $\mathrm{Fe}_{49.7-}$ $\mathrm{Cr}_{18} \mathrm{Mn}_{1.9} \mathrm{Mo}_{7.4} \mathrm{~W}_{1.6} \mathrm{~B}_{15.2} \mathrm{C}_{3.8} \mathrm{Si}_{2.4}$ (at.\%) amorphous coating and hard chromium coating in $3.5 \mathrm{wt} \% \mathrm{NaCl}$ solution was systematically investigated. The components of the passive films formed at various polarization potentials were analyzed. The conclusions are summarized as follows:

1. Compared with the hard chromium coating, the SAM2X5 Fe-based amorphous coating exhibits a wide and stable passive region with much lower passive current density in the potentiodynamic polarization and showed a considerably lower current density at various anodic potentials in the potentiostatic polarization.

2. The passive films formed at various potentials for the SAM2X5 Fe-based amorphous coatings exhibits very different thickness. As applied potential increases, the thickness of the passive film increases initially and then decreases because of the preferential dissolution of the high-valent oxides.

3. The Mo and $\mathrm{W}$ enhanced the passivity of SAM2X5 Febased amorphous coating both at low potentials as well as at high potentials. The two elements Mo and $\mathrm{W}$ facilitate the formation of compact and stable $\mathrm{Cr}_{2} \mathrm{O}_{3}$ passive film at low potentials, and the relatively stable hexavalent molybdenum and tungsten improve the protectiveness of the passive films at high potentials.

4. The Mn element can improve the stability of the passive films. The substantial enrichment of $\mathrm{Mn}$ both in the outer passive films and in the inner passive films contributes to the stable passivation of the Fe-based amorphous coating.
Acknowledgements This work was supported by the National Natural Science Foundation of China (Nos. 51471166, 51131006 and 51171119) and the College Youth Scholar Fostering Program of Liaoning Province (No. LJQ2014015). The authors thank W.H. Sun and B.J. Yang for their assistance in the coating preparation.

\section{References}

[1] A. Inoue, B.L. Shen, C.T. Chang, Acta Mater. 52, 4093 (2004)

[2] S.J. Pang, T. Zhang, K. Asami, A. Inoue, Acta Mater. 50, 489 (2002)

[3] J.R. Scully, A. Gebert, J.H. Payer, J. Mater. Res. 22, 302 (2007)

[4] C. Suryanarayana, A. Inoue, Int. Mater. Rev. 58, 131 (2013)

[5] H.S. Ni, X.H. Liu, X.C. Chang, W.L. Hou, W. Liu, J.Q. Wang, J. Alloys Compd. 467, 163 (2009)

[6] K.V. Arun, C.S. Venkatesha, J. Mater. Process. Technol. 207, $336(2008)$

[7] S.A. Katz, H. Salem, J. Appl. Toxicol. 13, 217 (1993)

[8] N. Espallargas, J. Berget, J.M. Guilemany, A.V. Benedetti, P.H. Suegama, Surf. Coat. Technol. 202, 1405 (2008)

[9] J.M. Guilemany, N. Espallargas, P.H. Suegama, A.V. Benedetti, J. Fernandez, J. Therm. Spray Technol. 14, 335 (2005)

[10] C. Zhang, K.C. Chan, Y. Wu, L. Liu, Acta Mater. 60, 4152 (2012)

[11] G. Wang, Z. Huang, P. Xiao, X. Zhu, J. Manuf. Process. 22, 34 (2016)

[12] S.D. Zhang, J. Wu, W.B. Qi, J.Q. Wang, Corros. Sci. 110, 57 (2016)

[13] J. Farmer, J.S. Choi, C. Saw, J. Haslam, D. Day, P. Hailey, T. Lian, R. Rebak, J. Perepezko, J. Payer, D. Branagan, B. Beardsley, A. D'Amato, L. Aprigliano, Metall. Mater. Trans. A 40, 1289 (2009)

[14] S.D. Zhang, W.L. Zhang, S.G. Wang, X.J. Gu, J.Q. Wang, Corros. Sci. 93, 211 (2015)

[15] Y. Wang, S.L. Jiang, Y.G. Zheng, W. Ke, W.H. Sun, J.Q. Wang, Corros. Sci. 63, 159 (2012)

[16] J. Farmer, J. Haslam, S. Day, T. Lian, C. Saw, P. Hailey, J. Choi, R. Rebak, N. Yang, J. Payer, J. Mater. Res. 22, 2297 (2007)

[17] K. Hashimoto, Corrosion 58, 715 (2002)

[18] C.O.A. Olsson, D. Landolt, Electrochim. Acta 48, 1093 (2003)

[19] U.R. Evans, G.M. Schmid, N. Hackerman, J. Electrochem. Soc. 109, 544 (1962)

[20] M.J. Duarte, J. Klemm, S.O. Klemm, K.J.J. Mayrhofer, M. Stratmann, S. Borodin, A.H. Romero, M. Madinehei, D. Crespo, J. Serrano, S.S.A. Gerstl, P.P. Choi, D. Raabe, F.U. Renner, Science 341, 372 (2013)

[21] K. Hashimoto, K. Asami, K. Teramoto, Corros. Sci. 19(1), 3-14 (1979)

[22] J.N. Wanklyn, Corros. Sci. 21, 211 (1981)

[23] C.R. Clayton, Y.C. Lu, J. Electrochem. Soc. 133, 2465 (1986)

[24] G.P. Halada, C.R. Clayton, J. Vac. Sci. Technol. A 11, 2342 (1993)

[25] N. Bui, A. Irhzo, F. Dabosi, Y. Limouzin-Maire, Corrosion 39, 491 (1983)

[26] M.P. Ryan, D.E. Williams, R.J. Chater, B.M. Hutton, D.S. McPhail, Nature 415, 770 (2002)

[27] A. Pardo, M.C. Merino, A.E. Coy, F. Viejo, R. Arrabal, E. Matykina, Corros. Sci. 50, 1796 (2008)

[28] J. Zhang, W. Zhang, C. Yan, K. Du, F. Wang, Electrochim. Acta 55, 560 (2009)

[29] H. Fang, X. Hui, G. Chen, J. Alloys Compd. 464, 292 (2008)

[30] Z.B. Zheng, Y.G. Zheng, W.H. Sun, J.Q. Wang, Corros. Sci. 82, 115 (2014) 
[31] Z.M. Wang, J. Zhang, X.C. Chang, W.L. Hou, J.Q. Wang, Corros. Sci. 52, 1342 (2010)

[32] T.S. Li, L. Liu, B. Zhang, Y. Li, X.L. Wang, F.H. Wang, Electrochem. Commun. 52, 80 (2015)

[33] N. Wint, A.C.A. de Vooys, H.N. McMurray, Electrochem. Acta 203, 326 (2016)

[34] S.C. Kwon, M. Kim, S.U. Park, D.Y. Kim, D. Kim, K.S. Nam, Y. Choi, Surf. Coat. Technol. 183, 151 (2004)

[35] C.D. Stockbridge, P.B. Sewell, M. Cohen, J. Electrochem. Soc. 108, 928 (1961)

[36] B. Brox, I. Olefjord, Surf. Interface Anal. 13, 3 (1988)

[37] K. Hashimoto, K. Asami, A. Kawashima, H. Habazaki, E. Akiyama, Corros. Sci. 49, 42 (2007)

[38] H.J. Park, H.W. Lee, J. Electrochem. Soc. 9, 6687 (2014)

[39] K. Asami, M. Naka, K. Hashimoto, T. Masumoto, J. Electrochem. Soc. 127, 2130 (1980)
[40] H. Habazaki, A. Kawashima, K. Asami, K. Hashimoto, J. Electrochem. Soc. 138, 76 (1991)

[41] K. Asami, K. Hashimoto, S. Shimodaira, Corros. Sci. 17, 713 (1977)

[42] S.D. Zhang, Z.M. Wang, X.C. Chang, W.L. Hou, J.Q. Wang, Corros. Sci. 53, 3007 (2011)

[43] M.R. Alexander, G.E. Thompson, X. Zhou, G. Beamson, N. Fairley, Surf. Interface Anal. 34, 485 (2002)

[44] M. Bojinov, G. Fabricius, T. Laitinen, T. Saario, J. Electrochem. Soc. 145, 2043 (1998)

[45] R. Goetz, J. Laurent, D. Landolt, Corros. Sci. 25, 1115 (1985)

[46] Z.M. Wang, Y.T. Ma, J. Zhang, W.L. Hou, X.C. Chang, J.Q. Wang, Electrochim. Acta 54, 261 (2008) 